\title{
INFORMAÇÃO-HAPPENING E O ROMANCE DA CIÊNCIA DA INFORMAÇÃO
}

\author{
Igor Soares Amorim ${ }^{1}$ \\ Solange Puntel Mostafa ${ }^{2}$
}

\begin{abstract}
Resumo: Neste ensaio, pretende-se conceber o conceito de informação-happening à filosofia da ciência da informação. A introdução já nos apresenta o conceito destacando sua potência em relação à perspectiva representacional. Questiona-se o debate em torno da interdisciplinaridade, que toma como ponto central as identidades, e não os efeitos resultantes dos contados entre os diferentes planos, os artísticos, os científicos e os filosóficos, que são as produções do pensamento. Afirma-se a existência de uma ciência da informação nômade, aberta ao acontecimento e ao universo não-bibliográfico, pela qual propõe-se o conceito de informaçãohappening.
\end{abstract}

Palavras-Chave: Informação-Happening. Informação. Filosofia da Ciência da Informação. Acontecimento.

\section{INTRODUÇÃO}

Informação-happening é um conceito filosófico e os conceitos são como personagens dos romances na medida em que resolvem problemas, sem o apelo às soluções universais. Em cada romance, uma história, um drama, um problema a ser descrito. Traçar a ciência da informação como um romance implica em dramatizá-la filosoficamente. Conceber o conceito como uma singularidade, sem ter nada de universal permitiu a Gilles Deleuze pensar a filosofia como romance especulativo, por conceitos. O livro filosófico pensado tal como um livro de ficção cientifica, dada a virtude antecipativa do conceito, que para tal precisa ser criado, construído pois os conceitos não estão prontos e nem designam a representar as coisas existentes. O conceito é um não-existente no sentido em que, sendo virtual, ele apenas insiste e assim subexiste, ou seja, não desaparece com as soluções. Pois só pode-se criar conceitos diante de problemas mal colocados. O conceito traz em si o problema para o qual ele é um caso de solução. E logo diremos que a interdisciplinaridade da ciência da informação é um problema mal colocado que precisa de novos conceitos para traçar novos planos entre as grandes formas de pensamento. Filosofar é praticar um certo futurismo pois "pensa-se do fundo do não-saber e sobre o que não se sabe nem se pode saber", como é a agradável escrita de Souza (1995 p.16). Deleuze reconhece que o empirismo inglês na figura de David Hume, já trazia um comportamento romanesco para a filosofia, fazendo da filosofia, o romance dos

\footnotetext{
1 Doutorando e Mestre em Ciência da Informação pelo Programa de Pós-Graduação em Ciência da Informação da Universidade Federal de Santa Catarina (PGCIN/UFSC).

${ }^{2}$ Doutora em Educação pela Pontifícia Universidade Católica de São Paulo (PUC). 


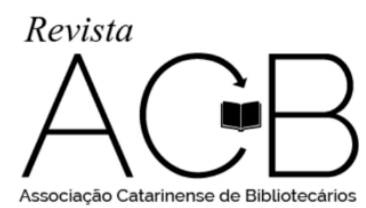

Revista ACB: Biblioteconomia em Santa Catarina, Florianópolis, v. 22, n. 3, p. 467-482, ago./nov., 2017.

romances. Pois o empirismo inglês construiu uma teoria das relações entre os objetos e elas são exteriores aos termos relacionados, um ganho importante para a ciência da informação na construção de suas linguagens documentárias, especialmente se pensarmos nas relações associativas dos tesauros, em que as relações são exteriores aos termos relacionados. Só valem as relações entre os fatos não eles mesmos.

Observar a relação entre as ciências e a diferença que elas relações vão produzindo nas próprias ciências. Isto traz um grau de devir no mundo, nas circunstâncias, nas ações e paixões, como fatores de variações das próprias relações. Apesar de ficção do pensamento, a filosofia aqui praticada pressupõe uma orientação imediatamente prática e não representacionista, pois não é sua intenção construir teorias de explicação do mundo e de seus fenômenos. A filosofia deleuziana não teoriza, não leva ao universal, aliás, ela luta contra os universais justamente através de construção de conceitos que são sempre fragmentados, parciais e locais. Os conceitos são acontecimentos. Por isso o conceito fillosófico de nossa reflexão intitula-se 'informação happening'. Desde que entendamos que acontecimentos não são as coisas que nos acontece, não é o que se passou e nem o que está na iminência de acontecer. Está entre ambos, as duas coisas ao mesmo tempo, daí seu caractere paradoxal, experimental e pluralista. Trata-se de uma filosofia acontecimental em que o pensamento torna-se uma ficção, sempre experimentando novas relações entre os seres, construindo novas composições.

\section{INTERDISCIPLINARIDADE OU DESLIZAMENTO DE PLANOS?}

A natureza interdisciplinar da ciência da informação percebida por Borko (1968) desde os anos sessenta vem sendo confirmada ao longo das últimas décadas por muitos autores e nos parece exemplo quiçá de um problema mal colocado, pois impossibilita pensar o devir da ciência da informação, uma vez que fixa as identidades tanto da ciência da informação quanto das ciências que com ela se relacionam. E impossibilita pensar a ciência da informação filosoficamente, pois a filosofia precisa de outro plano que não o disciplinar das ciências. Mas como diz o próprio Borko (1968), trata-se de relações entre campos científicos semelhantes, em que pese não vermos tanta proximidade entre Matemática e Linguística, por exemplo ou entre Artes Gráficas e Psicologia. Mas é claro que numa concepção representacionista as disciplinas listadas por Borko adequam-se bem no plano de referencia das ciências. Assim, matemática, lógica, linguística, psicologia, ciência da computação, engenharia da produção, artes gráficas, comunicação, biblioteconomia, administração, e outros campos científicos semelhantes compõem a lista do autor. 


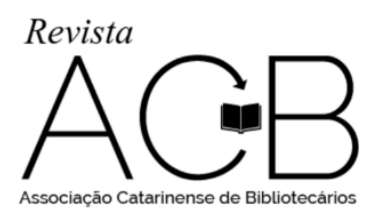

Revista ACB: Biblioteconomia em Santa Catarina, Florianópolis, v. 22, n. 3, p. 467-482, ago./nov., 2017.

Para nós, já não se trata mais de perguntar pelo ser da ciência da informação como possuindo um domínio próprio, mas observar as modificações nesta ciência toda vez que ela diverge de si mesma, ao se aproximar de outros planos de pensamento, científicos, filosóficos ou artísticos. Interessa-nos abandonar os falsos problemas enredados nas últimas décadas com relação à identidade da ciência da informação, seja o problema inexistente da sua identidade social, seja o falso problema de sua identificação epistemológica. Interessa-nos cuidar do acidental na dinâmica prática-teórica de singularização dos procedimentos informacionais, como nos inspira Figueiredo (2013).

\section{ARTE E CIÊNCIA DA INFORMAÇÃO}

Trabalhos de conclusão de curso tem realizado a ligação entre as artes e a ciência da informação. Por exemplo, Bragiola (2012) intitula seu trabalho de conclusão Cinema e Ciência da Informação (2012); da mesma forma Lorenzeto (2013) analisa uma exposição de arte pictural em uma galeria com o título Curadoria de arte: a lógica do afeto para a Ciência da Informação e como se não bastasse, Almeida (2012) organiza um livro chamado Ciência da Informação e Literatura. Nessas três experiências vemos claramente uma ponte sendo lançada entre as artes e a ciência (no caso, a ciência da informação).

Lemos também na dissertação de Amorim (2015) sob o título de Análise de domínio sob a luz do conceito de agenciamento de Gilles Deleuze uma relação entre a ciência da informação (com o conceito de análise de domínio) e a filosofia da diferença. Assim, parece que as artes, as ciências e a filosofia se relacionam de alguma maneira. Mas como? Encontramos alguns textos explicando a relação entre a literatura e a filosofia. Por exemplo, Camargo (2012, s/p) explica as diferenças e semelhanças entre ambas às atividades dizendo que, apesar de ambas usarem a "linguagem para comunicar algo a alguém, na Filosofia, o principal objetivo é expressar conceitos, ideias. Na literatura, existe a narrativa, isto é, o ato de contar uma história”. O autor lembra de alguns filósofos como Platão, cujos diálogos poderiam ser considerados a um só tempo literários e filosóficos. Já a filosofia de Kant ninguém ousaria dizer que o seu estilo é literário, "mas o que dizer de um Nietzsche? Poemas e aforismos, tão frequentemente empregados pelo autor do Zaratustra, são formas literárias" (idem). Camargo (idem) prossegue dizendo que "Rousseau foi autor de um romance de sucesso na época: A bela Heloísa. Sartre tornou-se conhecido não apenas por sua filosofia, mas também pelos seus romances. E poucos escritores são tão filosóficos como Thomas Mann e Machado de Assis". 


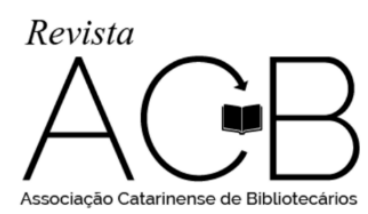

Revista ACB: Biblioteconomia em Santa Catarina, Florianópolis, v. 22, n. 3, p. 467-482, ago./nov., 2017.

Eis aí a nossa questão: alguns escritores colocam questões filosóficas em seus escritos. Concordamos com Camargo sobre os escritos híbridos mencionados por ele, e concordarmos também com a sua conclusão sobre as diferenças entre literatura e filosofia:

Aqui encontramos uma diferença fundamental entre filosofia e literatura: não se lê uma obra filosófica da maneira como se lê um romance. É preciso voltar no texto, ir aos comentadores, comparar o que é dito em um trecho com o que é dito em outro, verificar a repercussão que as ideias filosóficas tiveram na época em que foram propostas e nas gerações posteriores. Geralmente, não se faz isso durante a leitura de um romance, conto ou poema (CAMARGO, 2012).

Pensamos, no entanto, que as diferenças entre literatura e filosofia não estão voltadas apenas ao ato de ler. Silva (2009), ao analisar o livro Melancolia e apocalipse: estudos sobre o pensamento português e brasileiro de Leonel Ribeiro dos Santos, também se refere à relação entre literatura e filosofia, já que o autor Leonel é um filósofo português discorrendo sobre aspectos estéticos da literatura portuguesa e brasileira. Segundo Silva (2009, p. 327) "Não se trata de uma disciplina iluminar a outra, nem de recobrimento ou absorção de uma pela outra, pois aqui, definitivamente, a literatura não é o outro da filosofia”. Para Silva (idem).

Trata-se, ao contrário, de perceber que há desde o surgimento da Estética no final do século XVIII... um remanejamento das hierarquias no campo do conhecimento que culmina com a efetuação de uma equivalência entre as duas, de modo que tanto a literatura como a filosofia são, a partir de então, essencialmente produção e exposição de pensamento.

Tanto Bragiola (2012), quanto Lorenzetto (2013) quanto Amorim (2015) admitem, inspirados pela filosofia de Gilles Deleuze que arte, ciência ou filosofia são formas de Pensamento, sem qualquer hierarquia entre elas. Vejamos uma parte do resumo de Bragiola:

O presente trabalho é resultado do estudo da teoria de Deleuze, Barthes, Mostafa e Nova Cruz como um deslizamento de planos. Para isso usou-se a teoria da imagem-tempo, o punctum, e a informação afeto respectivamente. $\mathrm{O}$ intuito foi de aproximar essas teorias para que houvesse um possível dialogo entre esses pensadores e assim transportar essa teoria para o universo da ciência da informação e da documentação (BRAGIOLA, 2012, p. 6).

Lorenzetto inicia o resumo do seu trabalho de conclusão de curso mencionando uma lógica diferenciada de tratamento da informação, "não somente a informação como um corpo atual, composta por metadados, mas também a informação como corpo virtual, composta somente por elementos que 


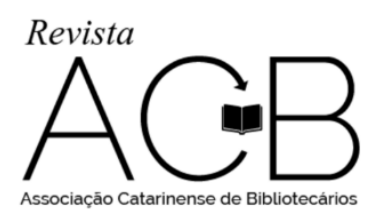

Revista ACB: Biblioteconomia em Santa Catarina, Florianópolis, v. 22, n. 3, p. 467-482, ago./nov., 2017.

provocam sensações. A esta informação, foi designado o termo Informação-Afeto" (LORENZETTO, 2013, p. 58).

Ao colocar arte como pensamento, Silva (2009) inspirou-nos ler textos sobre o cruzamento da ciência da informação e as artes. São textos que reproduzem o quadro delineado por Mostafa e Nova Cruz (2009, p. 96) obre o deslizamento de planos entre as três formas de pensamento. É visível no quadro mencionado que as três formas de pensamento, de alguma maneira se relacionam com o caos. Pensar é dar consistência ao caos. A filosofia traz conceitos do caos, a arte retira de lá perceptos e afetos e a ciência faz projeções. A filosofia e a arte têm muitas afinidades por causa da maneira como enfrentam o caos, sendo este entendido não como anarquia ou confusão, mas como um meio de velocidade infinita. Pensar é enfrentar esse meio de velocidade infinita, dando-lhe consistência. A filosofia não quer perder o infinito ao traçar conceitos sobre a vida, e as artes, por sua vez, trazem uma parcela do caos (ou do infinito) para a obra do artista, seja um quadro, seja um conto literário. Cabe à ciência perder o infinito, desacelerar por assim dizer, de modo a resolver os problemas do vivido em referencias espaço-temporais determinadas (DELEUZE; GUATTARI, 2010).

Para Amorim (2015, p. 140) "há interferência das três multiplicidades (arte, filosofia e ciência), umas nas outras, mas o pensamento exige que tais cruzamentos devem proceder com seus próprios meios". Isto quer dizer que:

[...] o filósofo, mesmo que for criar um conceito de alguma sensação, deve estabelecer seu plano de imanência, levantar os componentes com seu personagem conceitual e desenhar seu conceito, assim como deve ocorrer na Arte e na Ciência. Por isso as multiplicidades se implicam de modo extrínseco (AMORIM, 2015, p. 141).

Amorim (ibidem, p. 121) ainda explica que "As três disciplinas se distinguem pela maneira como enfrentam o caos, pela relação com o caos no qual o cérebro mergulha". Já Lorenzetto (ibidem, p. 15) entende que "os planos de pensamento se conectam, pois todos são dotados de propriedades comuns e deslizam uns sobre os outros, configurando-se como forças criadoras, cada qual com suas particularidades, a partir das propriedades intrínsecas às suas formas". Lorenzetto (idem) enfatiza também que "O movimento se dá já no pensamento, pois não existe uma linearidade no ato de pensar que faça com que os três deslizamentos se separem. No entanto, analisados isoladamente, tratam-se de elementos distintos".

Mostafa; Nova Cruz; Amorim (2015, p. 368) revisam essas três formas de pensamento colocando esta análise como um dos grandes legados da filosofia da diferença: para eles, “a existência é pensada por 


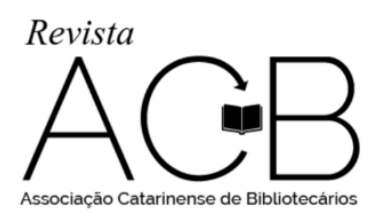

Revista ACB: Biblioteconomia em Santa Catarina, Florianópolis, v. 22, n. 3, p. 467-482, ago./nov., 2017.

três formas distintas, cada qual ocupada em organizar o caos virtual das intensidades e forças infinitas que perpassam nossas existências de uma forma particular". Ainda dizem os três autores que "Enquanto a ciência se ocupa em resolver problemas, em modificar o estado das coisas com suas funções, equações e soluções, a arte produz e mexe com afetos e perceptos". Quanto à fillosofia, "Sobra, então, para a filosofia - e só para ela - a tarefa de produzir conceitos e de construir um plano no qual esses conceitos sejam abrigados". Chamou-nos atenção o trecho em que os autores destacam o desaceleramento do cientista ao voltar do caos. "O cientista da informação desacelera as virtualidades em nome da referência" (idem).

Buscamos através desta pequena revisão sobre o pensamento entender as relações entre arte e filosofia, dado o carácter filosófico presente na obra de muitos artistas. Conceitos filosóficos deslizam sobre perceptos artísticos ou blocos de sensação como são chamados os resultados da atividade artística.

\section{A CIÊNCIA NÔMADE VERSUS A CIÊNCIA OFICIAL}

A questão do nomadismo perpassa também as ciências, tanto quanto as artes e a filosofia. $\mathrm{Na}$ filosofia da diferença, como Deleuze nos fala ao longo de sua obra, é preciso produzir a diferença. Isso é necessário também nas ciências, questionando as ciências oficiais, de carácter bem definidas e que funcionam a partir das regularidades do real. Ao discutir a nomadologia de Deleuze, Oneto (2008, p. 154) apresenta as quatro características básicas das ciências oficiais:

1) enxerga a realidade como um "sólido", podendo mesmo ser definida como uma teoria dos sólidos; 2) pretende constituir modelos estáveis, homogêneos, eternos, sempre à cata de invariantes; 3) faz da realidade algo de plenamente mensurável, pressupondo um espaço linear, fechado, em que vamos de retas a paralelas - espaço estriado (métrico), em que a mensuração prepara para uma ocupação sedentária; 4) é um modelo teoremático de ciência, isto é, baseado numa racionalidade pressuposta, para a qual os problemas não passam de obstáculos a serem superados rumo ao elemento essencial.

Em contrapartida, afirma o autor, "os nômades praticam ciência de uma maneira que supõe outra concepção, excêntrica, mais próxima do que denominamos artes. Seu modo de formalização é vago". Oneto (idem) apresenta então as quatro características da ciência nômade:

1) a realidade é vista como um conjunto de fluxos (devires), ensejando um modelo hidráulico; 2) sua matéria é heterogênea, sem forma preestabelecida; 3) isto implica um modelo turbilhonar, operando num espaço visto como liso (topológico) que é ocupado sem ser contado ou medido, que se delineia em função da distribuição de fluxos; 4) 


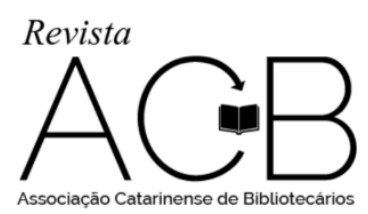

Revista ACB: Biblioteconomia em Santa Catarina, Florianópolis, v. 22, n. 3, p. 467-482, ago./nov., 2017.

constitui-se como um modelo problemático, isto é, como um modelo para o qual pensar é problematizar sem que a razão nada possua de direito

\subsection{Ciência da Informação Nômade}

Ciência da informação nômade é uma feliz expressão encontrada em Faucher (2013). Não podia ser expressão mais apropriada para pensarmos a ciência da informação, dentro de uma abordagem deleuziana. Há duas maneiras de entender os livros e as bibliotecas: no paradigma da ciência oficial ou da ciência nomádica. A oficial entende o livro como portador de um assunto definido, quase sempre hierarquizado numa matriz classificatória e encerrado em sim mesmo portador que é de uma unidade significativa. Já na ciência nomádica o livro é multiplicidade e, como tal, os capítulos do livro podem ser lidos como se escolhe uma música num aplicativo, sem qualquer preocupação com sequenciamentos já que lê-se e escreve-se signos como sinais - é isso que tipifica o comportamento nômade. "Para o nômade, leitura e escrita são apenas duas faces do mesmo ato"3 (FAUCHER, 2013, p. 245, tradução nossa). Talvez esteja se referindo à agilidade dos processos de ler e escrever como instrumentos de praticar a vida útil: "Trilhas de animais, um sinal de fumaça, o pisoteado sob o escovado, os restos de um acampamento tudo isso são apenas sinais que o nômade interpreta, mas também escreve diretamente na decisão"4 (idem, p. 245, tradução nossa). O autor propõe que consideremos a biblioteca "uma máquina de guerra", como é o conceito do nomadismo deleuziano. Mesmo para o sedentarismo dos construtores de bibliotecas bem assentadas no silêncio e na imobilidade dos livros em suas matrizes classificatórias, a biblioteca pode ser considerada uma "máquina de guerra", esse conceito criado por Deleuze e Guattari (2012) que não tem nada a ver com o militarismo de uma guerra, mas com o combate em favor da criação do novo, bem pode se aplicar aos livros e aos procedimentos organizacionais.

\subsection{O nomadismo da Biblioteca de Babel no exemplo de Faucher}

Ao analisar a Biblioteca de Babel do poeta argentino Luís Borges, Faucher (2013) menciona que a noção de infinito ali contida é simplista, pois deixa intocável o significado mesmo da biblioteca. Falta à biblioteca de Babel um dos ingredientes para a determinação do sentido. O modelo de permutação pelo qual os livros aparecem na biblioteca de Babel ainda é platônico, pois o sistema baseia-se em variação,

\footnotetext{
3 "For the nomad, reading and writing are but two faces of the same act"

4 "animal traks, a smoke signal, the trampled underbrushed, the remains of a campsite - all these are but signs the nomad interprets, but also writes directly into decision".
} 


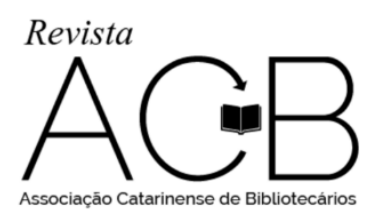

Revista ACB: Biblioteconomia em Santa Catarina, Florianópolis, v. 22, n. 3, p. 467-482, ago./nov., 2017.

não em diferença. Deleuze e Guattari privilegiam a composição e o encontro mais do que a permutação e a derivação. Faucher também considera que Borges não provê uma etiologia de como a biblioteca emerge, sendo que o bibliotecário infeliz fica parado no meio, perseguindo o fantasma do significado entre o passado e o futuro. Contudo, talvez isto não seja incompetência do bibliotecário, mas a própria estrutura do acontecimento. Tal biblioteca pode ser vista como um acontecimento, na medida em que escapa do presente na permanente visitação ao passado e ao futuro ao mesmo tempo. Como é o paradoxo de Alice no País das Maravilhas ao afirmar os dois sentidos ao mesmo tempo. Alice não cresce sem que fique menor. "O paradoxo deste puro devir, com a sua capacidade de furtar-se ao presente, é a identidade infinita: identidade infinita dos dois sentidos ao mesmo tempo, do futuro e do passado, da véspera e do amanhã, do mais e do menos...” (DELEUZE, 2007, p. 2).

Há uma afirmação interessante no Abecedário de Deleuze no verbete acontecimento: "Então não se perguntará qual o sentido de um acontecimento: o acontecimento é o próprio sentido" (DELEUZE, 1988, p. 4). O sentido da Biblioteca de Babel é que ela é o próprio acontecimento. Não algo que acontece (acidente), o acontecimento "ele é no que acontece o puro expresso que nos dá sinal e os espera" (DELEUZE, 2007, p. 152). Acontecimento-efeito. Efeito que é como um "eterno retorno como o mais terrível labirinto de que falava Borges, muito diferente do retorno circular de Cronos: eterno retorno que não é mais o dos indivíduos, das pessoas e dos mundos, mas o dos acontecimentos puros que o instante deslocado sobre a linha não cessa de dividir em já passados e ainda por vir.” (idem, p. 182)

A identidade da Biblioteca de Babel é metafísica e não técnica. Ela é acontecimento. Um tipo de simulacro, um verdadeiro 'corpo sem órgãos' -- para usar mais um conceito filosófico de Deleuze --, sinônimo de virtual. Considerando a biblioteca um corpo sem órgãos, ou talvez um uma biblioteca sem livros, no sentido tradicional do que entendemos por livros, estamos diante de um clássico fluxo de produção, onde atuam um meio virtual determinado se diferenciando em atualizações no real. Como explica Faucher (2013), o narrador experimenta a vertigem dos objetos parciais que são os livros, sem reconhecer as operações inerentes ao virtual.

O mais importante para o cientista da informação nômade ao adentrar a biblioteca de Babel não seriam as propriedades dos livros (autor, assunto e outros códigos editoriais) identificados e distribuídos como parte de um catálogo. Mas apenas e tão somente as relações emergentes. Estas relações já não seriam configuradas de acordo com a lógica da identidade clássica. Ao eleger a diferença como princípio de constituição do mundo, a filosofia de Deleuze não pode aceitar que as relações de tal constituição se baseiem na identidade através da negação. Pois este procedimento dialético é o que, segundo o filósofo da diferença, precisaria ser evitado, para afirmar a diferença sem necessidade de usar a negação. Isto é um 


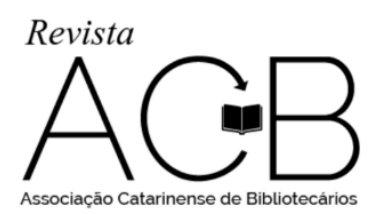

Revista ACB: Biblioteconomia em Santa Catarina, Florianópolis, v. 22, n. 3, p. 467-482, ago./nov., 2017.

livro porque não é um lápis, por exemplo, é uma afirmação pela negação, procedimento inaceitável: “A” é diferente de "B" pois "B" é um "não-A" (PETROSKI, 2013, p. 23). Do ponto de vista ontológico, o nomadismo é uma teoria da anti-representação ou anti-princípio-da-identidade, como coloca Petroski (2013). Um cientista da informação nômade entenderia que os livros não são o mais importante, mas os fluxos em que eles se constituem, as relações elas mesmas. Inclusive as relações dos livros com o mundo não-bibliográfico, como reclama Latour (2000) e aqueles que falaram nas exterioridades do livro. Afinal, há todo um emaranhado que circunda o livro e o conecta com diferentes atores humanos e não humanos.

\section{FLUXOS DE INFORMAÇÃO-HAPPENING}

O mundo não-biográfico do livro, este fora do livro, nos interessa. A partir dele podemos fazer a ciência da informação nômade e propor conceitos sobre o plano filosófica da ciência da informação. Informação-happening é uma proposta não apenas para lembra-nos que há um acontecimento que é presente e atemporal na informação, antes dessa emitir sinais, mas depois de sua concepção. Também é um conceito que nasce em contato com o plano das artes, mas especificamente com o movimento happening. A escolha desse movimento das artes plásticas se dá por sua transgressão, seus artistas romperam os limites entre arte e mundo concreto por meio da ação, esta quase sempre marcada por sua simplicidade. O grupo Fluxus foi um dos maiores responsáveis pelo happening, justificando o título da seção. A obra Yard (1961) de Allan Kaprow (figura 1) consistia numa gama de pneus espalhados aleatoriamente pelo chão e num convite aos visitantes para saltarem sobre eles. $\mathrm{O}$ artista inspirava-se na técnica de "gotejamento" aplicadas na pintura por Pollock, agora traduzida tridimensionalmente, envolvendo materiais da vida cotidiana e a ação dos visitantes. A obra se abre ao acaso (THE ART STORY FOUNDATION, 2017).

Figura 1: Yard (1961), de Allan Kaprow

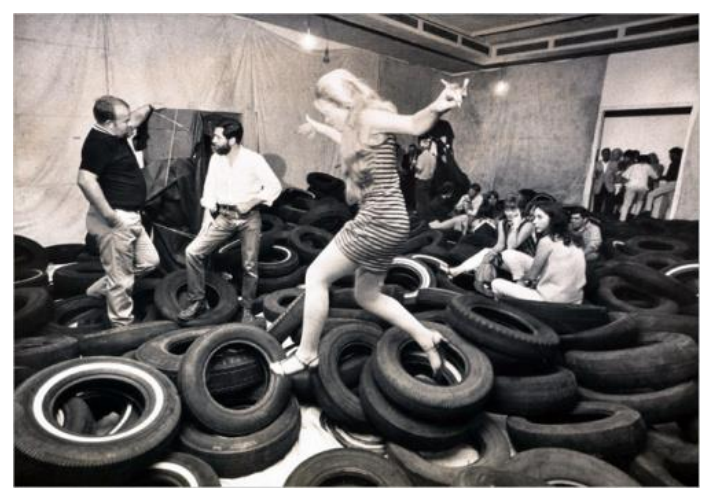

Fonte: <http://www.artsjournal.com/artopia/2009/10/allan_kaprow_the_retread.html>. 


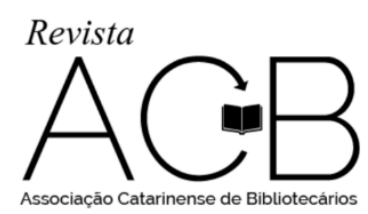

Revista ACB: Biblioteconomia em Santa Catarina, Florianópolis, v. 22, n. 3, p. 467-482, ago./nov., 2017.

Há no happening uma preocupação que anima o movimento, pois aqui evidencia que a arte está na ação, não na representação. Ação que não permite relações de sujeito-objeto, mas antes um fluxo que conecta e mistura humanos e não-humanos, a arte, o artista, os objetos e o público. Há uma exteriorização que abre a arte às forças do caos. Não há problemas de identidade ou epistemológicos, apenas as forças em devir, manifestas em cada salto aleatório sobre os pneus, saltos também sobre os planos filosóficos, artísticos e científicos. Há uma linha criadora que se move em direção as forças do caos, que captura tais forças em agenciamentos que envolvem os compostos heterogêneos, assim, o movimento happening

Não é abstrato nem figurativo, não é trágico nem cômico. Renova-se em cada ocasião. Toda pessoa presente a um happening participa dele. [...] Num happening, pode-se mudar de "estado" à vontade. Cada um no seu tempo e ritmo. (GLUSBERG, 1982, p. 32, apud Ribeiro, 2010).

A obra de arte no happening é um vir a ser, um devir, promovido pela diferenciação. É o processo de atualização, o fluxo de vida que anima o pensamento. A informação da ciência da informação oficial é objetivada enquanto elemento científico, ora sintetizado num sinal matemático, num impulso psíquico ou num consenso a uma comunidade. Mas há um acontecimento informacional, informação-happening, há intensidades que se condensam para o aparecimento de uma informação, num vazio presente, entre o passado e o futuro. Aqui não interessa a forma da sua manifestação, mas seu processo de atualização. Esse processo eleva ao último grau as condições materiais de produção da informação, na medida em que adentra ao caos intensivo.

Propomos a informação-happening, conceito que toca no real sem a obstrução de uma representação, que tardia a experiência, o conhecimento. A informação-happening ocorre na comunidade, nos pacotes psíquicos de conhecimentos, nos sinais matemáticos, ela enquanto materialidade atravessa toda a materialidade numa dada situação, é local e não universal; ela enlaça as materialidades na medida em que emerge do virtual. É um processo de captura de um fluxo intensivo, que resulta na estratificação de sinais, símbolos e ícones, os quais vão (re)organizar as redes citadas por Latour. A informaçãohappening é um acontecimento (DELEUZE, 2007), na medida em que salta entre o tempo Aion e Crono, é a diferença incluída no sistema. Mas ainda, enquanto acontecimento, marca a intemporalidade do tempo, que é o tempo próprio do acontecimento. A informação-happening pode exprimir a informaçãocoisa, assim como a informação-afeto. Todavia, antes de ser coisa, a informação é acontecimento, é conceito filosófico, que subsiste, insiste, e que exprime a existência das outras tantas informações descobertas e aquelas que ainda o serão. 


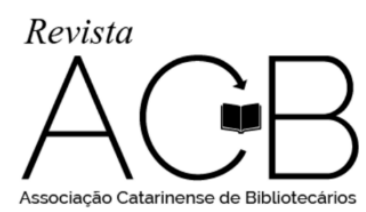

Revista ACB: Biblioteconomia em Santa Catarina, Florianópolis, v. 22, n. 3, p. 467-482, ago./nov., 2017.

Seguimos não mais os objetos do conhecimento, mas problemas de pensamento, que motiva a criação conceitual. Conforme destaca Deleuze (1992), conceitos não mais presos as identidades ou as essências, mas um conceito que reune as variáveis circunstânciais e que diga o acontecimento. Os conceitos se relacionam por vibrações que Deleuze e Guattari (2010) designam como vizinhaças. A vizinhaça interfere no problema-conceito. Informação-happening se avizinha com algos conceitos importantes, tal como representado na figura 2.

Figura 2: conceitos vizinhos da informação-happening

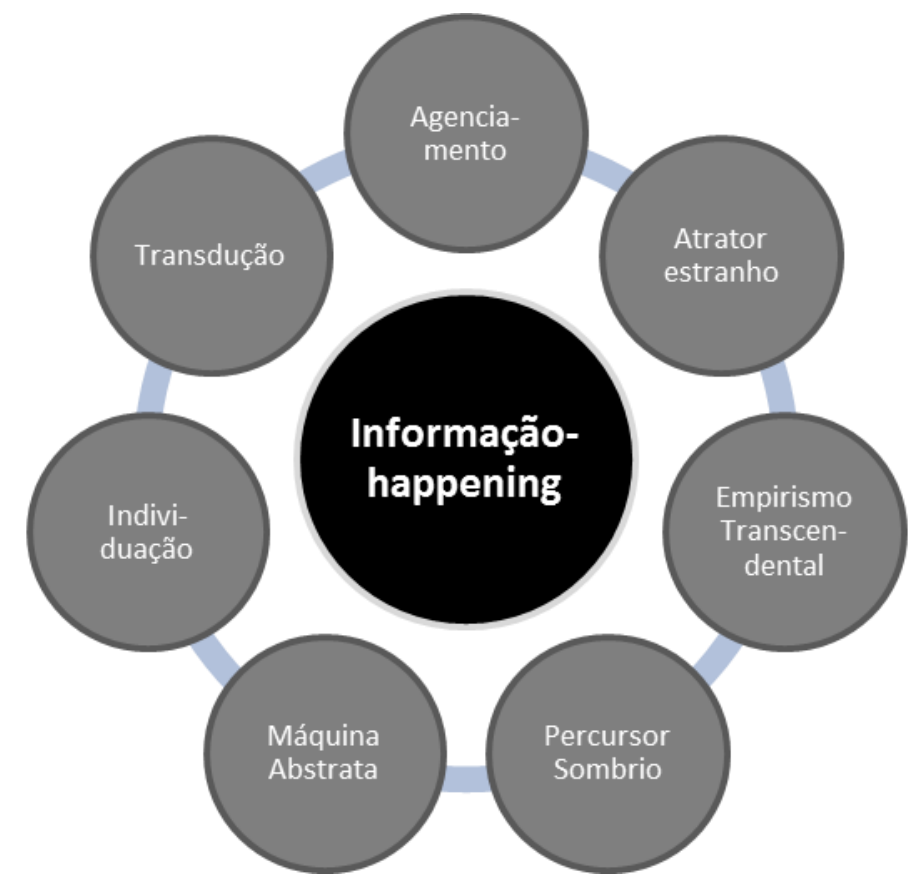

Fonte: elaborado pelos autores.

Agenciamento refere-se a articulação de heterogênos que são articulados por uma máquina abstrata e formam corpos, conteúdos e expressões nos processos de atualização (do virtual ao atual). Máquina abstrata é a matéria pura que ignora as formas e as substâncias que provocam o processo de emergencia dos planos do pensamento. Empirismo transcendental ou superior é o empirismo que Deleuze extraiu de Hume, que privilegia as relações e associações entre os objetos e seres do mundo, preferencialmente aos objetos e seres, equivale a dizer que as relações entre os termos são exteriores aos termos relacionados. Individuação é o nome dado a processos pelos quais os indiferenciados se tornam indivíduos e transdução é a individuação em progresso. Atrator estranho refere-se ao comportamento de 


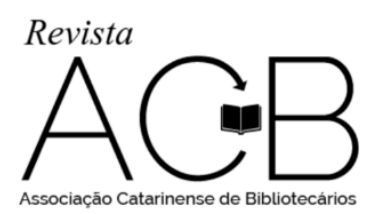

Revista ACB: Biblioteconomia em Santa Catarina, Florianópolis, v. 22, n. 3, p. 467-482, ago./nov., 2017.

um sistema dinâmico com tendência para convergir para um ponto (atrator). Finalmente, precursor sombrio diz respeito aos agentes de comunicação entre séries heterogêneas; a intensidade da diferença.

Para Deleuze e Guattari (2011a; 2011b), há uma distinção entre matéria informada e a formada. A primeira constitui o plano de consistência (da filosofia, arte e ciência), e é desorganizada, uma espécie de plasma anárquico. Ela também contém algo diferente da matéria formada, os "materiais" que emergem do substrato. Formada a matéria ela é uma dupla articulação de conteúdo e de expressão, essa articulação dupla é o proprio agenciamento. O conteúdo é geralmente molecular na natureza e a expressão assume uma qualidade nitidamente molar (linguagem). $\mathrm{O}$ que existe entre esses elementos não formados são velocidades relativas. Deleuze \& Guattari falam em "matéria não formada", e estas desempenham um papel em sua compreensão da relação forma-conteúdo, ao rejeitarem o helimorfismo aristotélico (o qual ensina que a forma in-forma a matéria). A forma em Deleuze e Guattari (2011a; 2011b) surge apenas através de um processo de desdobramento. Informações conectam o processo movendo-se do precursor sombrio em direção ao atrator estranho, cobrindo a ambos (sendo que o atrator já não seria um movimento em direção ao equilíbrio). Na formulação Simondon-Deleuze, a informação não só faz a diferença, ela é a própria diferença - ou, melhor, a informação é a seleção diferencial dentro do meio em que o coisa é constituída como ressonância entre conteúdo e expressão, sempre em uma composição de agenciamentos.

A informação é sempre um 'happening' ou um acontecimento imprevisível perfazendo a captura de fluxos intensivos que se passam no mundo. De tudo o que se falou da Teoria Matemática da Informação, com seus canais, ruídos e sinais sobrecodificando as mensagens e fixando posições de emissores e receptores, nada disso alcança o virtual e suas intensidades. Não precisamos falar em sinais e canais porque a informação chega antes de qualquer sinal a ser transmitido. A informação só significa a captura de fluxos intensivos por ser um potencial selecionado que, inicialmente organiza o conteúdo da mensagem a ser transmitida como sinal. Se no virtual as velocidades são infinitas, os agenciamentos ou combinações de ideias que ali se passam são uma forma de organizações e de desorganização. Se pensarmos a informação não em termos de graus ou níveis de organização, mas como diferencial ou diferença no sistema, isto permite-nos entender melhor a dramatização no circuito virtual-intensidadesatual, dramatização esta que explica as relações entre a ideia e as coisas que a ideia cria. Muito se disse sobre Informação como algo que dá forma à matéria, na inspiração aristotélica. Mas foi com o empirismo transcendental de Deleuze em sua parceria com Simondon que a matéria tornou-se independente da forma. A matéria é informativa, disse, Michel Buckand, o mestre dos neodocumentalistas. Com isso, Buckland (1991) adentra, intuitivamente, numa das teses mais importantes de Simondon na reversão do 


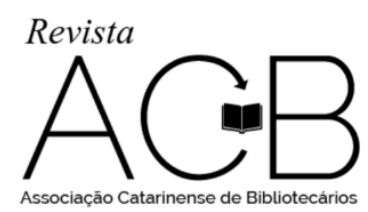

Revista ACB: Biblioteconomia em Santa Catarina, Florianópolis, v. 22, n. 3, p. 467-482, ago./nov., 2017.

platonismo e do aristotelismo. Sim, a forma não vem de fora para modelar a matéria, ela já está trabalhada na matéria de maneira intensiva. Nossa informação-happenig insiste em pleitear um lugar de honra no circuito virtual-intensidades-atual. Não temos nada contra a informação-coisa de Buckland (1991). Mas achamos que toda informação-coisa tem um aspecto ou uma face inefetuada e inefetuável, face inatual e intempestiva, acontecimental, numa palavra: virtual.

Quando consideramos a informação-coisa, estamos nos aproximando do caos e fixando-o em intervalos finitos para medir estados de coisas, muito útil por sinal. Mas quando conceitos e perspectivas são postos de lado em favor apenas de funções e proposições, como supõe a informação-coisa, perguntamos se esta redução não estaria excluindo o conceito de imanência e subvertendo as velocidades infinitas do devir, diluindo o que ocorre em meio ao caos das matérias não formadas do virtual, eliminando a informação-happening. A informação-happening é uma máquina abstrata e a questão toda é que ela precisa encontrar o seu fora, o seu exterior e, assim, permitir abrir os agenciamentos à diferença. Esta abordagem deleuziana preliminar sobre a informação problematiza a informação como redução de incertezas porque aposta na multiplicação da incerteza para avançar decididamente em direção à criação de novos agenciamentos. A informação-happening é potencialmente infinita e sua atualização nas coisas do mundo (seja numa equação matemática ou um belo poema de Manoel Barros) depende e é determinado pelas relações das próprias coisas. Esta teorização deleuziana que vai do virtual ao atual e deste para o virtual e que pensa a informação, filosoficamente, como um terceiro elemento da física se aproxima da genialidade de um Norbert Wiener, para quem a informação é informação, nem matéria, nem energia. A abordagem deleuziana desenvolvida por Faucher (2013) se aproxima de Wiener nesta compreensão de que informação é informação. Em diálogo com essa, dizemos: informação é antes um acontecimento. 


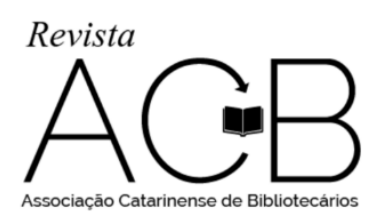

Revista ACB: Biblioteconomia em Santa Catarina, Florianópolis, v. 22, n. 3, p. 467-482, ago./nov., 2017.

\section{REFERENCIAS}

ALMEIDA, M. A. (Org.). Ciência da Informação e Literatura. Campinas, Alínea, 2012.

AMORIM, I. S. Análise de Domínio sob a Luz do Conceito de Agenciamento de Gilles Deleuze.

2015. 238 p. Dissertação (Mestrado em Ciência da Informação) - Universidade Federal de Santa Catarina. Florianópolis. 2015.

BORKO, H. Information science: what is it? American Documentation, v. 19, n. 1, p. 3-5, 1968.

BRAGIOLA, K. E. Cinema e ciência da informação. 2012. 90 p. Trabalho de Conclusão de Curso. (Graduação em Ciências da Informação e da Documentação) - Faculdade de Filosofia Ciências e Letras de Ribeirão Preto - USP. .Ribeirao Preto. 2012.

BUCKLAND, Michael K. Information as thing. Journal of the American Society for Information Science, v. 42, n. 5, p. 351-360, June 1991.

CAMARGO, N. J. Filosofia e Literatura. Harmonia dos contrários [blog]. Disponível em: <http://harmoniadoscontrarios.blogspot.com.br/2012/03/filosofia-e-literatura.html>.

DELEUZE, G. Conversações. São Paulo: Editora 34, 1992.

DELEUZE, G. Lógica do sentido. São Paulo: Perspectiva, 2007.

DELEUZE, G. O abecedário de Gilles Deleuze: transcrição integral do vídeo, para fins exclusivamente didáticos. Éditions Montparnasse: Paris, 1988.

DELEUZE, G.; GUATTARI, F. Mil platôs: capitalismo e esquizofrenia 2. 2. ed.Rio de Janeiro: Editora 34, 2011a.

DELEUZE, G.; GUATTARI, F. Mil platôs: capitalismo e esquizofrenia 2. Rio de Janeiro: Editora 34,2011b.vol. 2.

DELEUZE, G.; GUATTARI, F. Mil platôs: capitalismo e esquizofrenia 2. Rio de Janeiro: Editora 34, 2012.vol. 5.

DELEUZE, G.; GUATTARI, F. O que é a filosofia? São Paulo: Ed. 34, 2010.

FAUCHER, K. X. Metastasis and metastability: a deleuzian approach to information. Springer Science \& Business Media, 2013.

FIGUEIREDO, Gláucia. Das alianças entre Pedagogia e Filosofia: dinâmica variabilística e precursor sombrio. Revista Fermentario, v. 2, n. 7, 2013. 


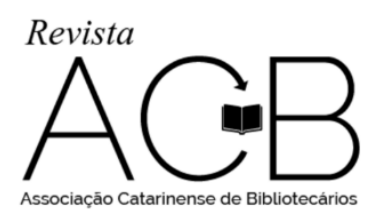

Revista ACB: Biblioteconomia em Santa Catarina, Florianópolis, v. 22, n. 3, p. 467-482, ago./nov., 2017.

LATOUR, B. Redes que a razão desconhece: laboratórios, bibliotecas, coleções. In: BARATIN, Marc \& Jacob, Christian (Org.) O poder das Bibliotecas: a memória dos livros no Ocidente. Rio de Janeiro: UFRJ, 2000.p. 21-44.

LORENZETTO, C. Curadoria de arte: a lógica do afeto para a ciência da informação. 2013. 103 p. Trabalho de Conclusão de Curso. (Graduação em Biblioteconomia, Ciências da Informação e da Documentação) - Faculdade de Filosofia, Ciências e Letras de Ribeirão Preto - USP. Ribeirão Preto. 2013.

MOSTAFA, S. P.; NOVACRUZ, D. Para entender a filosofia de Deleuze e Guattari. Campinas, Alínea, 2009.

MOSTAFA, S. P.; NOVACRUZ, D.; AMORIM. I.S. Primavera nos dentes: fuga e resistência na era Digital. Liinc em Revista, Rio de Janeiro, v.11, n.2, p. 360-374, 2015.

ONETO, P. D. A nomadologia de Deleuze-Guattari. Lugar Comum, v. 1, n. 23-24, p. 147-161, 2008.

PETROSKI, J. S. O encontro nômade entre Joge Luis Borges e Gilles Deleuze. 2013. 109 p.

Dissertação (Mestre em Estudos Literários) - Setor de Ciências Humanas, Letras e Artes, da Universidade Federal do Paraná. Curitiba. 2013.

RIBEIRO, F. C. Action painting, happening e performance art: da ação como fator significante à ação como obra nas artes visuais. Visualidades, v.8, n.2, p. 113-137, 2010.

SILVA, A. A. Literatura e filosofia: entre as razões do sentimento e os prazeres da inteligência. Estudos Avançados, v. 23, n. 66, p. 327-334, 2009.

SOUZA, Dias, Logica do acontecimento: uma introdução à filosofia de Deleuze. Lisboa: Documenta, 1995.

THE ART STORY FOUNDATION. The art story modern art insight [site]. 2017. Disponível em: <http://www.theartstory.org/movement-happenings-artworks.htm\#pnt_1>. 


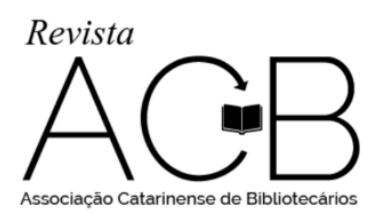

Revista ACB: Biblioteconomia em Santa Catarina, Florianópolis, v. 22, n. 3, p. 467-482, ago./nov., 2017.

\title{
INFORMATION-HAPPENING AND THE ROMANCE OF INFORMATION SCIENCE
}

\begin{abstract}
In this essay, we intend to conceive the concept of information-happening to the philosophy of information science. The introduction already presents the concept highlighting its potential in relation to the representational perspective. The debate on interdisciplinarity, which takes as its focal point the identities, and not the effects resulting from those between the different planes, the artistic, the scientific and the philosophical, which are the productions of thought, is questioned. We affirm the existence of a nomadic information science, open to the happening and to the non-bibliographic universe, through which the concept of information-happening is proposed.
\end{abstract}

Keywords: Information-Happening. Information. Philosophy of Information Science. Happening.

\section{IGOR SOARES LEMOS}

Doutorando em Ciência da Informação pelo Programa de Pós-Graduação em Ciência da Informação da Universidade Federal de Santa Catarina (PGCIN/UFSC). Mestre em Ciência da Informação pelo Programa de Pós-Graduação em Ciência da Informação da Universidade Federal de Santa Catarina (PGCIN/UFSC). Graduado em Ciência da Informação, Documentação e Biblioteconomia pela Universidade de São Paulo (USP). E-mail: igao.sa@gmail.com

\section{SOLANGE PUNTEL MOSTAFA}

Doutora em Educação (Filosofia da Educação) pela Pontifícia Universidade Católica de São Paulo (PUC). Mestre em Ciência da Informação pelo Instituto Brasileiro de Informação em Ciência e Tecnologia (IBICT). Graduada em Biblioteconomia e Documentação pela Escola de Biblioteconomia e Documentação de São Carlos. E-mail: smostafa@terra.com.br

\section{RECEBIDO EM: 24-03-2017}

\section{ACEITO EM: 05-05-2017}

